\title{
Advances in automatic detection of body condition score of cows: a mini review
}

\begin{abstract}
BCS is a method to estimate body fat stores and accumulated energy balance of cows. This value influences productivity, reproduction, and health of cows. Therefore, it is important to monitor BCS to achieve a better animal response. In practice, this task is performed by expert scorers mainly visually, and could vary between scorers and be time-consuming. For this reason, several studies have tried to automate BCS by applying image analysis and machine learning techniques. An overview of selected studies is provided in this mini review.
\end{abstract}

Keywords: precision livestock, body condition score, automatic detection, image analysis

\author{
Volume 5 Issue 4 - 2017 \\ Juan Rodríguez Alvarez, ${ }^{3}$ Mauricio Arroqui, ${ }^{1,3}$ \\ Pablo Mangudo, ${ }^{1,3}$ Juan Toloza, ${ }^{1,3}$ Daniel \\ Jatip, ${ }^{1,3}$ Juan M Rodríguez, ${ }^{2}$ Alejandro \\ Zunino, ${ }^{2}$ Cristian Mateos, ${ }^{2}$ Claudio \\ Machado 1,3 \\ 'Agencia Nacional de Promoción Científica y Tecnológica \\ (ANPCyT), Argentina \\ ${ }^{2}$ ISISTAN Research Institute - UNCPBA-CONICET, Argentina \\ ${ }^{3}$ CIVETAN Research Institute - FCV UNCPBA-CONICET-CIC, \\ Argentina
}

Correspondence: Juan Rodríguez Alvarez, CIVETAN Research Institute, FCV-UNCPBA-CONICET-CIC, Campus Universitario, Tandil, Buenos Aires, Argentina,

Email jmrodriguez.alvarez@gmail.com

Received: June 02, 2017 | Published: June 26, 2017
Abbreviations: $\mathrm{BCS}$, body condition score; ICT, information and communication technology; $3 \mathrm{D}$, three-dimensional

\section{Introduction}

The BCS system is a means of accurately determining body condition of cows, independent of body weight and frame size, ${ }^{1}$ using a 5-point scale with 0.25 point increments (with 1 representing emaciated cows and 5 representing obese cows). ${ }^{2,3}$ Extreme values of BCS are related with health risk, low productivity level and impaired pregnancy rate..$^{4-7}$ The subjectivity in the judgment of raters can lead to different scores for the same cow under consideration, or inconsistent scores of the same expert, which requires regular repeatability assessments. ${ }^{8}$ As a result of the increasing availability of wide range of information and communication technology (ICT), more and higher-quality information to be available is expected in support of daily decision-making. ${ }^{9}$ Consequently, there are multiple opportunities for automation and digitalization of livestock farming tasks, and different studies have particularly focused on automation of BCS. This brief review selects the most relevant and recent studies on the topic.

\section{Discussion}

Different authors have studied the feasibility of utilizing digital images to determine BCS. In this mini review relevant works later than 2007 and based on cow images from a top view were considered. In the Table 1 main characteristics and results from the selected papers are shown.

\section{Developed methods have two stages:}

i. Image analysis techniques to extract relevant characteristics (such as angles, distances and areas between anatomical points; intensity/depth pixels values; cow contour or a representation of it) to differentiate fat reserves levels of cows; Usage of collected characteristics to implement a BCS estimation model.

ii. Mostly, there are two types of models used: regression analysis models (as in) ${ }^{10-16}$ and algorithms that measure cow's body angularity (as in) ${ }^{17-19}$ according to the hypothesis that the body shape of a fatter cow is rounder than that of a thin cow. Moreover, three automation levels are described. In the lowest level are, ${ }^{10,12,15}$ which require to manually identify anatomical points in the images to extract characteristics to develop the estimation models. In the medium level are, ${ }^{11,13,20}$ where the input images used are manually selected, but the rest of the process is automatic. Finally, in the highest level are, ${ }^{14,16-19}$ where the process is completely automated. Among the latter studies, only ${ }^{17,18}$ carry out real time estimations (i.e. estimation result is showed to the user few seconds after the cow goes under the camera) because image preprocessing techniques (segmentation, normalization, features extraction) used in the other studies are time-consuming. In more recent studies the use of $3 \mathrm{D}$ cameras is more frequent. The use of thermal cameras, ${ }^{17,21}$ although allows an easy segmentation of the entire body of the cow (the warm cow shape highlight above its cold surroundings), are less common probably associated to a their higher costs. In Marilyn Krukowski ${ }^{11}$ and Dorota Anglart ${ }^{20}$ they used red breed dairy cows because the camera used to acquire the images has operational problems with black pigment cows. The selected studies applied different statistical metrics to estimate BCS visually observed by experts, and the most frequently used indicator was the accuracy of the automatic estimated scores to be within \pm 0.25 and within \pm 0.50 increment score of the manual BCS. However, more efficient computing processing methods based on powerful machine learning technique fated to improve BCS accuracy are under testing. ${ }^{22}$ 
Table I General characteristics and results of BCS estimation systems

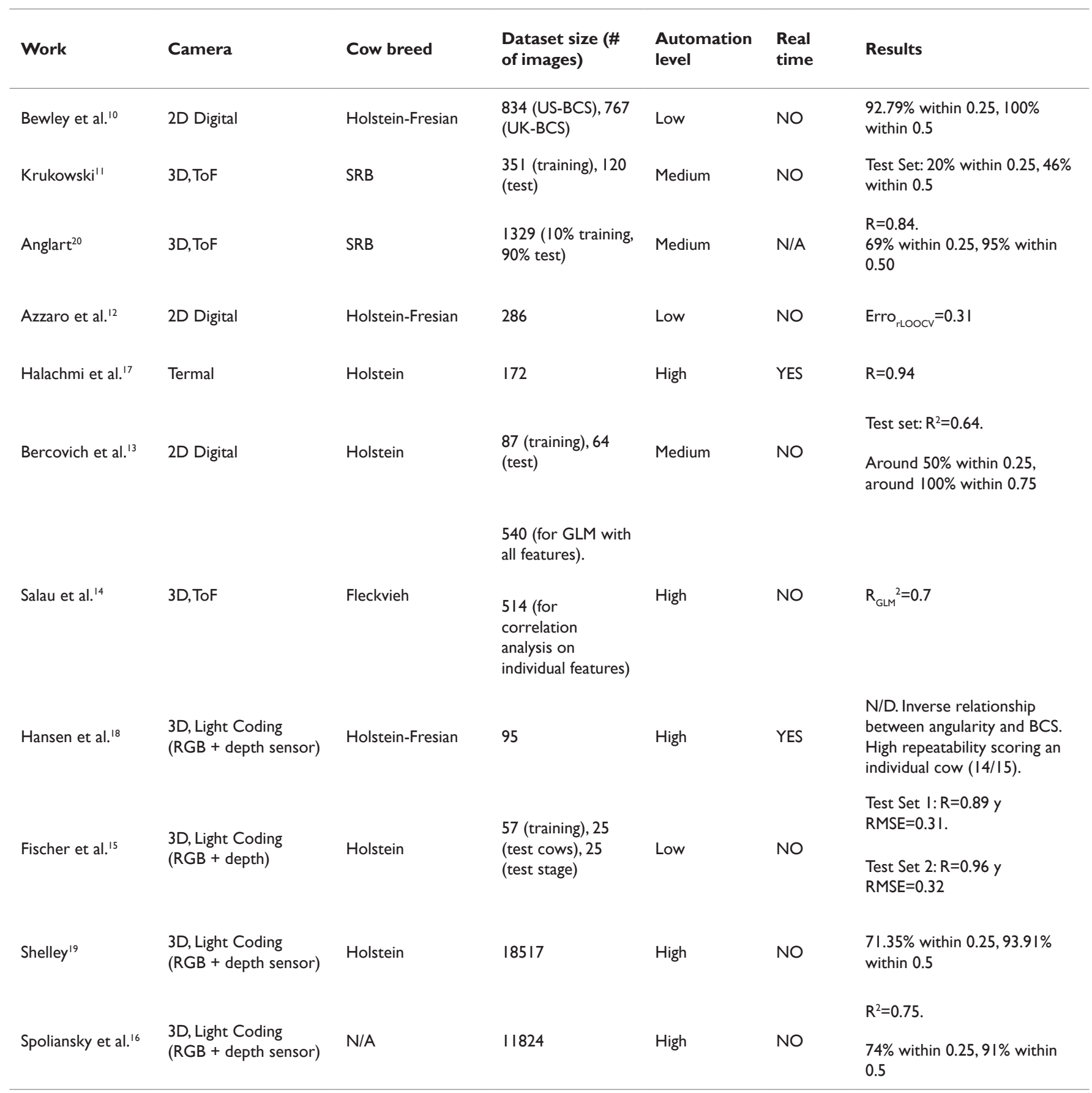

2D, two dimensional; 3D, three-dimensional; ToF, time-of-flight; SRB, swedish red breed; GLM, generalized linear model; US-BCS, united state body condition score; UK-BCS, united kingdom body condition score; R, correlation coefficient; $\mathrm{R}^{2}$, coefficient of determination; LOOCV, leave one out cross validation; RMSE, root mean square error

\section{Conclusion}

The literature attempts to automate BCS assessment look promising as a tool for supporting cattle decision-making, in a context where ICT technology is becoming more efficient, productive, and cheaper. Acceptable accuracy within the range of human error has been reported, with room for improvement as more effective computing processing methods became available.

\section{Acknowledgements}

None.

\section{Conflict of interest}

Author declares that there is no conflict of interest. 


\section{References}

1. EE Wildman, GM Jones, PE Wagner, et al. A dairy cow body condition scoring system and its relationship to selected production characteristics. Journal of Dairy Science. 1982;65(3):495-501.

2. James D Ferguson, David T Galligan, Neal Thomsen. Principal descriptors of body condition score in holstein cows. Journal of Dairy Science. 1994;77(9):2695-2703.

3. JD Ferguson, G Azzaro, G Licitra. Body condition assessment using digital images. Journal of dairy science. 2006;89(10):3833-3841.

4. AJ Heinrichs, C Jones, VA Ishler. Body condition scoring as a tool for dairy herd management. Technical report, Penn State College of Agricultural Sciences. 2017.

5. Wayne Kellogg. Body condition scoring with dairy cattle. Technical report, Division of Agriculture, University of Arkansas, 2010: 1-6 p.

6. O Markusfeld, N Galon, E Ezra. Body condition score, health, yield and fertility in dairy cows. The Veterinary Record. 1997;141(3):67-72.

7. John R Roche, Nicolas Charles Friggens, Jane K Kay, et al. Invited review: Body condition score and its association with dairy cow productivity, health, and welfare. J Dairy Sci. 2009;92(12):5769-5801.

8. E Vasseur, J Gibbons, J Rushen, et al. Development and implementation of a training program to ensure high repeatability of body condition scoring of dairy cows. J Dairy Sci. 2013;96(7):4725-4737.

9. Sander JC Janssen, Cheryl H Porter, Andrew D Moore, et al. Towards a new generation of agricultural system data, models and knowledge products: Information and communication technology. Agricultural Systems. 2016;155:200-212.

10. JM Bewley, AM Peacock, O Lewis, et al. Potential for estimation of body condition scores in dairy cattle from digital images. Journal of Dairy Science. 2008;91(9):3439-3453.

11. Marilyn Krukowski. Automatic determination of body condition score of dairy cows from 3d images. Master's thesis; 2009:1-89 p.
12. Azzaro G, Caccamo M, Ferguson JD, et al. Objective estimation of body condition score by modeling cow body shape from digital images. Journal of Dairy Science. 2011;94(4):2126-2137.

13. Bercovich A, Edan Y, Alchanatis V, et al. Development of an automatic cow body condition scoring using body shape signature and fourier descriptors. J Dairy Sci. 2013;96(12):8047-8059.

14. Salau J, Haas JH, Junge W, et al. Feasibility of automated body trait determination using the sr4k time-of-flight camera in cow barns. Springerplus. 2014;3:225.

15. Amélie Fischer, T Luginbühl, L Delattre, et al. Rear shape in 3 dimensions summarized by principal component analysis is a good predictor of body condition score in holstein dairy cows. J Dairy Sci. 2015;98(7):4465-4476.

16. Roii Spoliansky, Yael Edan, Yisrael Parmet, et al. Development of automatic body condition scoring using a low-cost 3-dimensional kinect camera. Journal of Dairy Science. 2016;99(9):7714-7725.

17. I Halachmi, M Klopčič, P Polak, et al. Automatic assessment of dairy cattle body condition score using thermal imaging. Computers and Electronics in Agriculture. 2013;99:35-40.

18. Mark Hansen, Melvyn Smith, Lyndon Smith, et al. Non-intrusive automated measurement of dairy cow body condition using $3 \mathrm{~d}$ video. Proceedings of the Machine Vision of Animals and their Behaviour (MVAB). 2015:1.1-1.8.

19. Anthony N Shelley. Incorporating machine vision in precision dairy farming technologies. PhD thesis, University of Kentucky. 2016.

20. Dorota Anglart. Automatic estimation of body weight and body condition score in dairy cows using 3d imaging technique. Master's thesis. 2010.

21. I Halachmi, P Polak, DJ Roberts, et al. Cow body shape and automation of condition scoring. J Dairy Sci. 2008;91(11):4444-4451.

22. Juan Rodríguez Alvarez, Mauricio Arroqui, Pablo Mangudo, et al. Body condition estimation on cows from 3d images using convolutional neural networks. I International Conference on Agro Big Data and Decision Support Systems in Agriculture. 2017. 